\title{
SITE OF ACTION OF DIAZEPAM IN THE PREVENTION OF LIDOCAINE INDUCED SEIZURE ACTIVITY IN CATS
}

\author{
Norman Wale, M.D. and Leonard C. Jenkins, M.D., C.M., F.R.C.P.(c) *
}

Diazepam (7-chloro-1-methyl-5-phenyl-3H-1,4-benzo-diazepin-2 (IH)-one) is the drug of choice in the treatment of status epilepticus. ${ }^{12}$ Recent studies indicate that diazepam is effective in the prevention of lidocaine induced convulsions. ${ }^{3}$

Previous experimental studies of the effects of diazepam on the central nervous system have used oral, ${ }^{4}$ intravenous ${ }^{5}$ or intraperitoneal routes of administration. Evidence from this type of study has suggested a diazepam specificity for lidocaine induced discharges arising from amygdala and hippocampus. ${ }^{6,7}$

Our objective has been to localize the site of action of diazepam by application of this drug to discrete regions of the CNS to block seizure activity induced by intravenously administered lidocaine in cats.

\section{MeTHODS}

Twelve adult mongrel cats of 2.6 to $3.6 \mathrm{Kg}$ body weight were used. Cortical electrodes and subcortical chemitrodes, of construction previously described ${ }^{8}$ were inserted using a David Kopf stereotaxic apparatus and Horsely Clarke coordinates as set forth in the stereotaxic atlas of Jasper and Ajmone-Manson..$^{9} \mathrm{~A}$ variety of sites were tested (brain stem reticular formation, amygdala, hippocampus, caudate nucleus, regio pre-optica). This generally involved bilateral implantation of two separate subcortical structures in each cat. The brain stem reticular formation was of particular interest in its role of wakefulness. The amygdala and hippocampus were particularly of interest because of their previously reported high sensitivity to the convulsive activity of intraperitoneal administered lidocaine. ${ }^{10}$

No experiments were performed within two weeks of surgery, and no experiments were done with less than $\mathbf{7 2}$ hours intervening after each previous experiment.

Cortical and sub-cortical electrical activity was recorded on a Grass Model 6 ink writing electroencephalograph. An electrocardiogram was recorded from shoulder leads and respiratory rates, monitored visually, were recorded on this same eight channel unit.

\section{(A) Lidocaine}

Lidocaine (Xylocaine - ASTRA) was chosen as a convulsogenic agent because of its widespread use in clinical anaesthesia, and because the seizure activity induced by it is of short duration. Lesser and larger doses of lidocaine hydrochloride

\footnotetext{
*Department of Anaesthesia, University of British Columbia, and Vancouver General Hospital.
} 


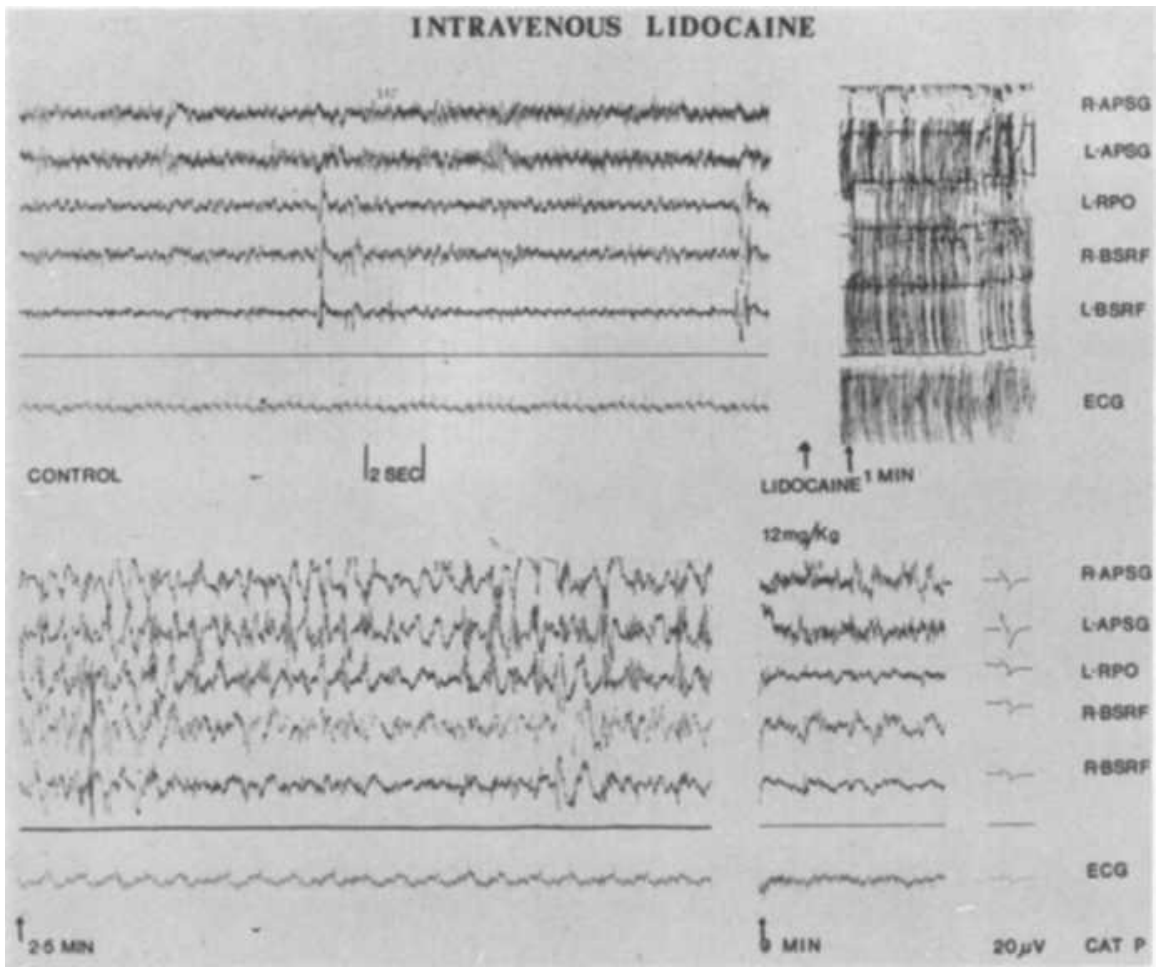

Figure 1. Intravenous Lidocaine: Evoked electrical activity following lidocaine $\mathrm{HCl} 12 \mathrm{mg} /$ $\mathrm{Kg}$ administered intravenously over 3 seconds. Voltages recorded from: APSG - antero-posterior sigmoid gyrus, RPO - regio pre-optica, BSRF - brain stem reticular formation.

2 per cent were administered intravenously over a three-second interval. The optimal dose was determined on the basis of being able to provide reproducible seizure activity of short duration rather than continual clonic seizure activity of such duration that central nervous system damage was liable to ensue.

\section{(B) Diazepam}

Diazepam (Valium, Hoffmann-La Roche $\mathrm{pH}$ 6.8) was applied bilaterally to a variety of subcortical sites, as was the placebo (Valium VehiclełHoffmann-La Roche $\mathrm{pH} 6.75)$. Each cat served as its own control.

Ten microlitres of solution containing $5 \mathrm{mg} / \mathrm{ml}$ were delivered from Hamilton microlitre syringes to the brain stem reticular formation, hippocampus, amygdala, hypothalamus and caudate nucleus 10 minutes prior to an intravenously administered convulsive dose of lidocaine.

Acute experiments were done in which cardiovascular, electroencephalographic and respiratory changes were noted following intravenously administered diazepam.

$\dagger 40$ per cent propylene glycol, 10 per cent ethyl alcohol, 15 per cent benzyl alcohol, 5 per cent sodium benzoate-benzoic acid, Q.S. to 100 per cent water. 


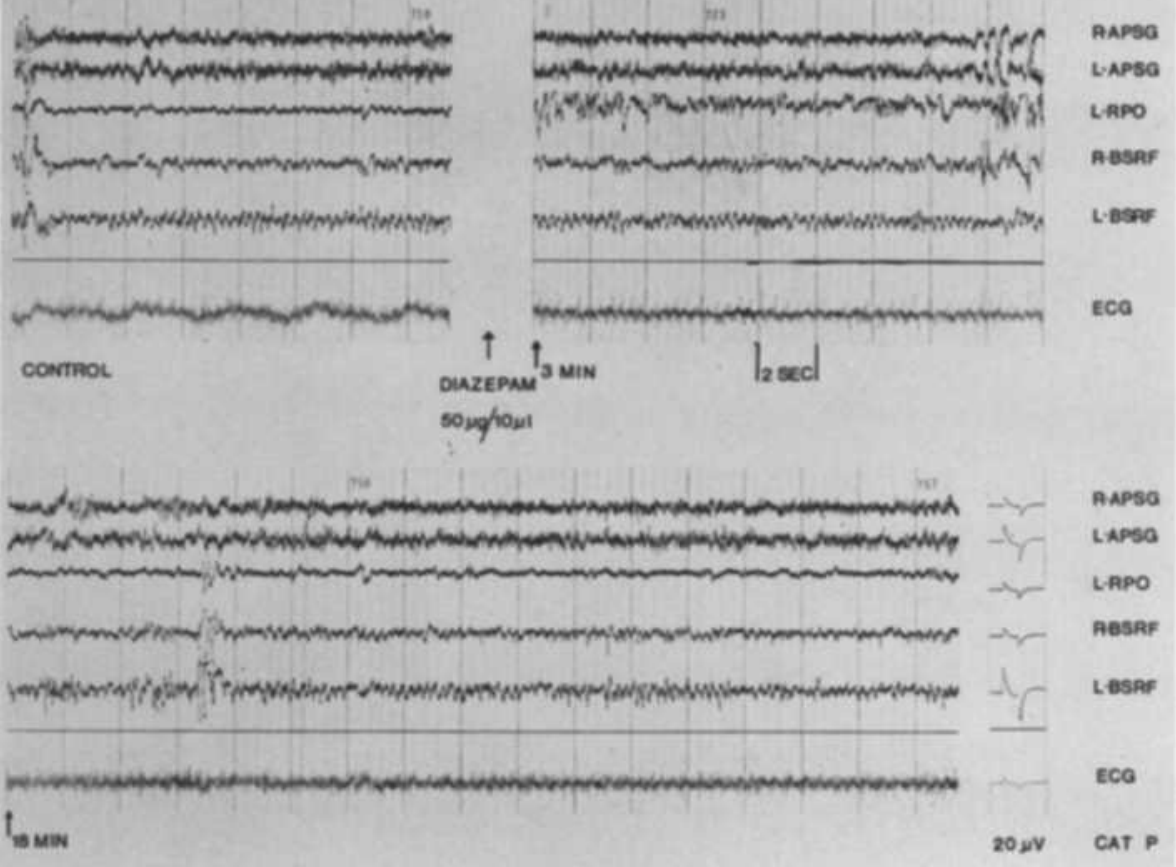

Figure 2. Diazepam in brain stem reticular formation. Recorded electrical activity following administration of diazepam $5 \mu \mathrm{l}$ to bilateral brain stem reticular formation. No discernible effect recorded.

\section{RESULtS}

Lidocaine: Intravenous administration of 2 per cent lidocaine over a threesecond interval in the dose of $12 \mathrm{mg}$ per $\mathrm{Kg}$ body weight produced a characteristic tonic extension of all extremities including the tail, and extension of the claws within each foot, within 20 seconds of completion of injection. This dose is in agreement with that previously reported by others as the threshold dose for seizure activity. ${ }^{11,12}$ Behavioural activity was manifest as tonic extension persisting for 40-60 seconds, frequently accompanied by coarse meowing. Mydriasis was common. Clonic activity was noted in several cats and was understood to indicate a lower threshold of CNS excitation in that particular cat. The electrical correlate of this is illustrated in Figure 1.

Diazepam: Intravenously administered diazepam $(1.5 \mathrm{mg} / \mathrm{Kg})$ invariably produced flaccid paralysis of immediate onset. Larger doses $(3 \mathrm{mg} / \mathrm{Kg}$ ) caused paralysis of up to 90 minutes, while only very large doses $(20 \mathrm{mg} / \mathrm{Kg}$ body weight) caused transient apnoea. Remarkable cardiovascular stability was noted in all cases, in keeping with earlier published observations. Topical administration of diazepam in a variety of subcortical sites was without electrical or behavioural effect in each of the sites tested (Figure 2).

Diazepam and Lidocaine: Complete blockade of the convulsive effect of intravenously administered lidocaine was established in every instance where diaze- 


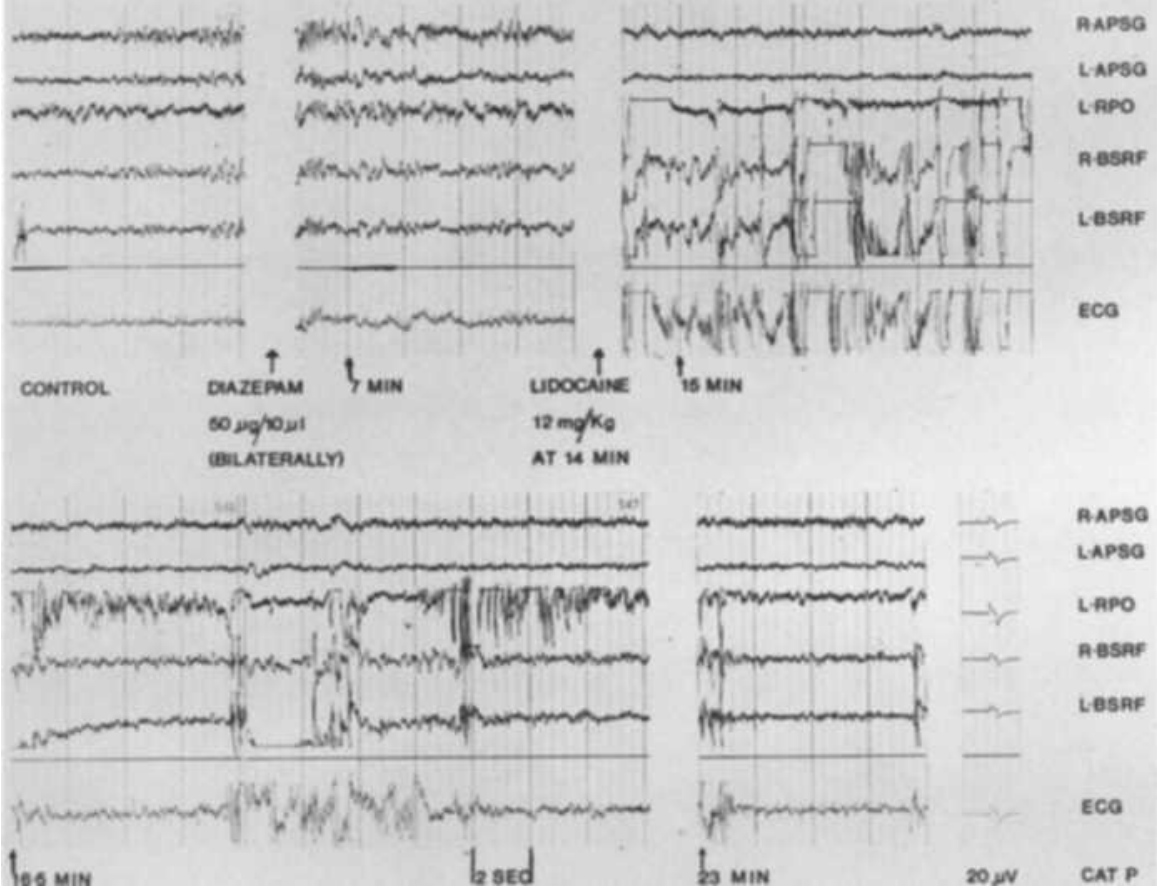

FIGURE 3. Diazepam in BSRF prior to intravenous lidocaine. Recorded electrical activity exhibiting virtually complete blockade of convulsogenic effect of intravenously administered lidocaine by prior bilateral application of diazepam to B.S.R.F.

pam was previously applied to bilateral brain stem reticular formation sites (Figure 3). Incomplete blockade of seizure activity was noted with injection of diazepam in the hippocampi (Figure 4) whereas no blockade was noted at other sites, including globus pallidus (Figure 5), nucleus ventralis postero lateralis, and regio preoptica (R.P.O.).

\section{Discussion}

Diazepam has been advocated in the therapy of status epilepticus because it is effective and does not cause respiratory or cardiovascular depression. It has been described as having "a generalized depressant action upon epileptogenic structures throughout the brain". ${ }^{13}$ Subsequent examination of the locus of action of diazepam led Przbyla and Wong ${ }^{7}$ to use mid-collicular decerebrated cats to conclude that "the brain stem reticular formation is the major locus of the central nervous system depressant action of diazepam". Even more recently Feinstein, Lenard and Mathias ${ }^{14}$ used intravenous diazepam $0.3 \mathrm{mg} / \mathrm{Kg}$ to protect against seizure activity of intraperitoneal procaine $(300 \mathrm{mg} / \mathrm{Kg}$ ) and lidocaine $(150 \mathrm{mg} /$ $\mathrm{Kg}$ ). These latter authors suggested that whereas lidocaine has been shown to have its most pronounced convulsogenic effect if administered to the hippocampi, it may be that diazepam exerts its anti-convulsant activity at the hippocampal sites. 


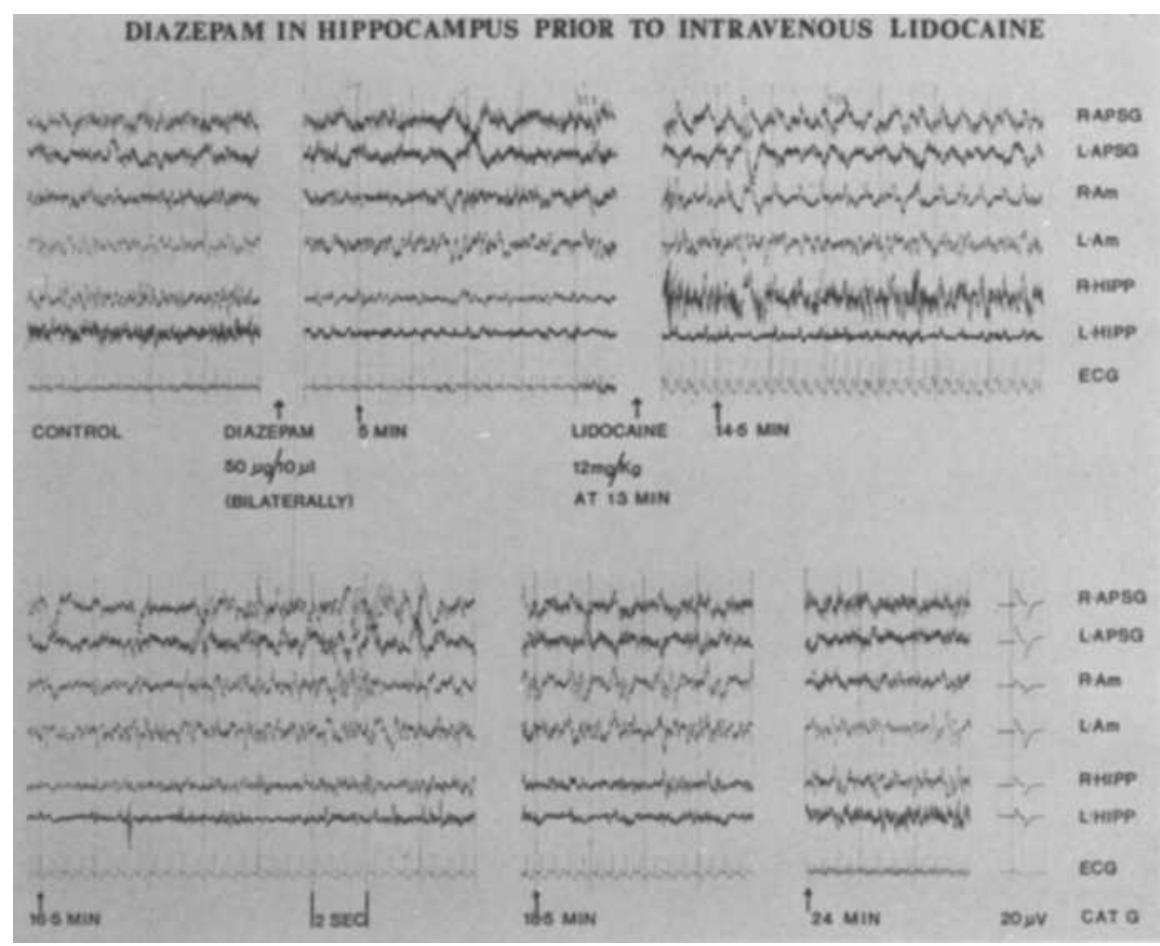

Figure 4. Diazepam in hippocampus prior to intravenous lidocaine. Recorded electrical activity showing partial blockade of convulsogenic effect of lidocaine by prior bilateral application of diazepam to hippocampi.

Support for the suggestion of diazepam action upon the limbic system has been put forward on the basis of electrical stimulation. ${ }^{6,15}$ In contradistinction from the thesis of the aforementioned authors, we suggest that diazepam exerts effect primarily at the level of the brain stem and to a lesser extent at the hippocampi.

\section{ConCLUSION}

Evidence from experimental studies in cats is presented that diazepam is capable of completely blocking the convulsogenic effect of intravenously administered lidocaine. This blocking activity is complete when diazepam is applied directly to the brain stem reticular formation, but is incomplete when applied to the hippocampus, and is absent at other sites (amygdala, hypothalamus) tested within the limbic system.

\section{SUMMARY}

Small volumes of diazepam were placed at a variety of sites within the central nervous system of cats, using a stereotaxic apparatus. The ability of diazepam so applied to prevent intravenous lidocaine induced seizures was most marked at brain stem reticular formation. 


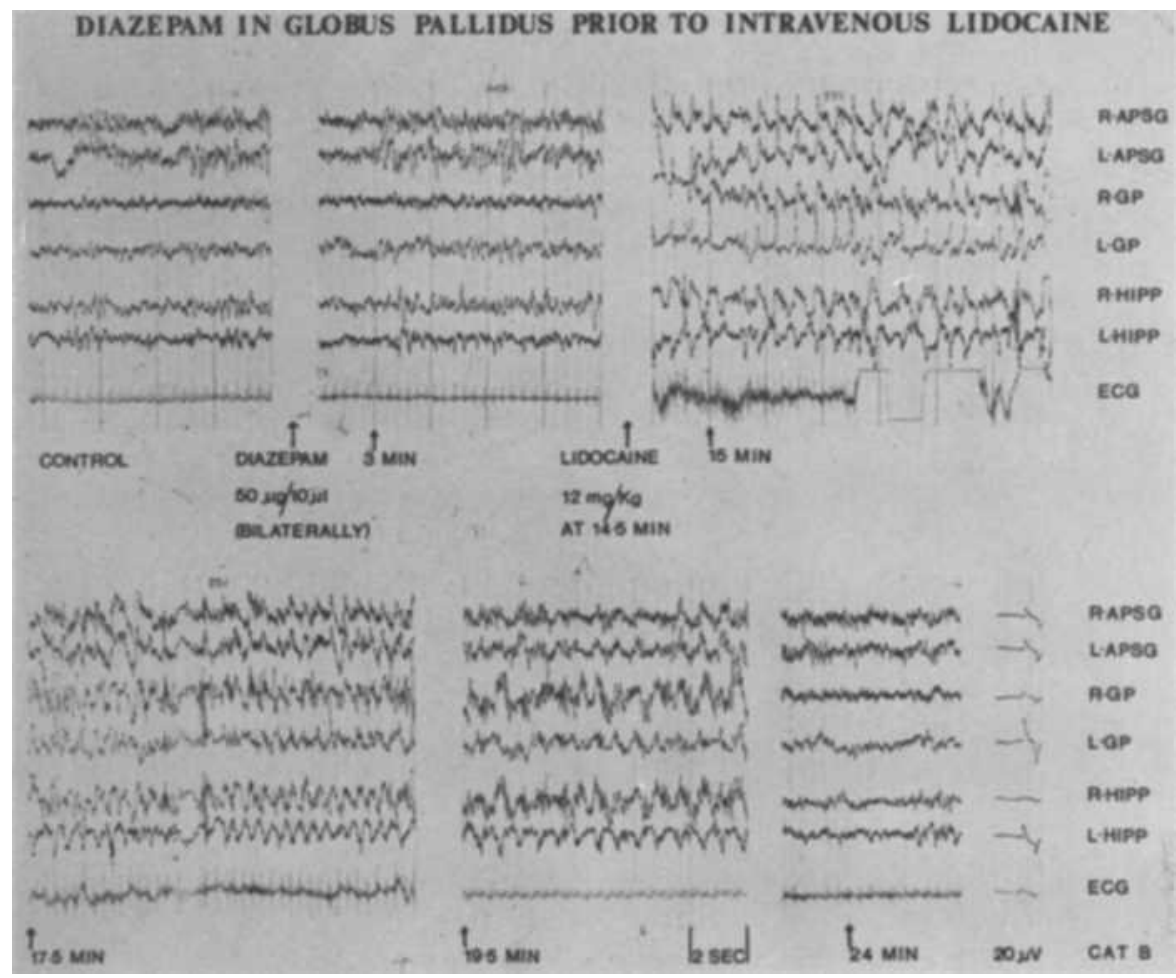

Figure 5. Diazepam in globus pallidus prior to intravenous lidocaine. Recorded electrical activity which demonstrated evoked electrical activity which has occurred in spite of prior bilateral application of diazepam to globus pallidus.

\section{RÉSUMÉ}

A l'aide d'un appareil stéréotaxique, nous avons placé de petites quantités de diazépam à différents endroits du système nerveux central de chats. L'endroit où le diazepam a le mieux réussi à prévenir les convulsions provoquées par l'administration de lidocaïne par voie endoveineuse a été la formation réticulée de la substance cérébrale.

\section{ACKNOWLEDGMENTS}

We are grateful to Dr. C.L. Dolman of the Department of Pathology, Vancouver General Hospital, and to Mrs. Maureen Murphy.

This work was in part financed by grants-in-aid from the Burroughs Wellcome Company (Canada) and Poulenc Limited of Montreal. Diazepam (Valium ${ }^{\circledR}$ ) and placebo were supplied by Hoffmann-La Roche.

\section{REFERENCES}

1. BELL, D.S. Dangers in the treatment of status epilepticus with diazepam. B.M.J. 1: 159 (1969).

2. Howard, F.M., Seybold, M.E., \& Reihen, J. The treatment of recurrent convulsion with intravenous injection of diazepam. Med. Clinic. N.A. 52: 977 (1968). 
3. DE Jong, R.H. \& Heavner, J.E. Diazepam prevents local anesthetic seizures. Anesthesiology 43: 523 (1971).

4. Schallex, W. \& Huehn, Alfred. Effects of benzodiazepines on spontaneous EEG and arousal responses of cats. Prog. in Brain Res. 18: 231 (1965).

5. Sharer, Leroy \& Kutt, Hens. Intravenous administration of diazepam, effects on penicillin-induced focal seizures in the cat. Arch. Neurol. 24: 169 (1971).

6. Morillo, A. Effects of benzodiazepine upon amygdala or hippocampus of the cat. Int. J. Neuropharmacol. 1: 353 ( 1962 ).

7. Przyblya, A.C. \& Wang, S.C. Locus of central depressant action of diazepam. J. Pharmacol. Exp. \& Therap. 163: 439 (1968).

8. Yamaguchi, N., Ling, G.M., \& MARCZYNSKI, T.J. Recruiting responses observed during wakefulness and sleep in unanaesthetized chronic cats. EEG Clin. Neurophysiol. 17: $246(1964)$.

9. Jasper, H.H. \& AJMONe-MARSan, C. A stereotaxic atlas of the diencephalon of the cat. Publ. Nat. Res. Council of Canada (1956).

10. Tuttle, W.W. \& Elliotr, H.W. Electrographic and behavioral study of convulsants in the cat. Anesthesiology 30: 48 (1969).

11. WAgman, I.H., DE Jong, R.H., \& Prince, D.A. Effects of lidocaine on the central narvous system. Anesthesiology 28: 155 (1967).

12. Acheson, Fiona, Bull, A.B., \& Glees, Paul. Electroencephalogram of the cat after intravenous injections of lidocaine and succinylcholine. Anesthesiology 17: 802 (1956).

13. Hernandez-Peon, R. et al. An experimental study of the anticonvulsive and relaxant actions of valium. Int. J. Neuropharmacol. 3: 405 (1964).

14. Fenstein, M.B., Lenard, W., \& Mathias, J. The antagonism of local anaesthetic induced convulsion by the benzodiazepine derivative diazepam. Arch. Int. Pharmacodyn. 187: 144 ( 1970$)$.

15. Schallex, W., Zabransky, F., \& Kuehn, A. Effects of benzodiazepines on central nervous system of cats. Arch. Int. Pharmacodyn. ?P: 467 (1964). 